\title{
RELAÇÕES CONCEITUAIS ENTRE EMPREENDEDORISMO SOCIAL E INOVAÇÃO SOCIAL
}

CONCEPTUAL RELATIONS BETWEEN SOCIAL ENTREPRENEURSHIP AND SOCIAL INNOVATION

Recebido em 05.06.2019 Aprovado 07.11.2019

Avaliado pelo sistema double blind review DOI: https://doi.org/10.12712/rpca.v13i4.28974

\author{
Indira Gandhi Bezerra-de-Sousa \\ indirabs@urc.uespi.br \\ Programa de Pós-Graduação em Administração-PPGADM/Universidade Federal do Paraná - Curitiba/Paraná, \\ Brasil \\ ORCID: https://orcid.org/0000-0001-7072-1514
}

\section{Rivanda Meira Teixeira}

rivandateixeira@gmail.com

Programa de Pós-Graduação em Administração-PPGADM/Universidade Federal do Paraná - Curitiba/Paraná, Brasil

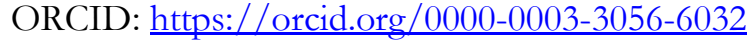

\section{Resumo}

Apesar da relevância crescente dos estudos sobre empreendedorismo social e inovação social de forma isolada constatou-se que existem lacunas de pesquisa na análise das duas temáticas de forma conjunta. Este estudo pretende analisar as relações conceituais entre empreendedorismo social e inovação social utilizando-se a revisão sistemática de literatura como estratégia de pesquisa. Como principais resultados pode-se destacar que existem diferenças entre as temáticas pesquisadas, principalmente se o estudo é teórico ou empírico. Além disso foram identificadas duas perspectivas que caracterizam a relação entre as temáticas estudadas: o empreendedorismo social visto como uma inovação social e o empreendedorismo social visto como um campo propício para geração de inovação social.

Palavras-chave: Empreendedorismo Social. Inovação Social. Revisão Sistemática da Literatura

\begin{abstract}
Despite the growing relevance of studies on social entrepreneurship and social innovation in isolation, it was found that there are research gaps in the analysis of the two themes together. This study aims to analyze the conceptual relationships between social entrepreneurship and social innovation using the systematic literature review as a research strategy. As the main results, it can be highlighted that there are differences between the researched themes, especially if the study is theoretical or empirical. In addition, two perspectives were identified that characterize the relationship between the themes studied: social entrepreneurship seen as social innovation and social entrepreneurship seen as a conducive field for generating social innovation.
\end{abstract}

Keywords: Social Entrepreneurship. Social Innovation. Systematic Literature Review 


\section{Introdução}

Várias iniciativas surgiram no campo prático no intuito de amenizar os problemas sociais e solucionar os desafios do século XXI (Cunha \& Benneworth, 2014), e entre elas, podem ser identificadas o empreendedorismo social e a inovação social. O empreendedorismo social, considerado subcampo do empreendedorismo (Dacin, Dacin \& Tracey, 2011; Dees, 1998; Dees, 2001; Mair \& Marti, 2006), referese à atividade empreendedora que tem como fim solucionar problemas sociais (Mair \& Marti, 2006). O empreendedor é o principal ator dessa atividade, pois é a partir da sua motivação que se consegue alcançar os resultados sociais almejados (Dacin, Dacin \& Matear, 2010).

O estudo desse fenômeno encontra-se em estágio de amadurecimento devido a sua ascensão nas últimas três décadas (Lubberink, Blok, Van Ophem, Van der Velde, \& Omta, 2018; Macke, Sarate, Domeneghini, J., \& da Silva, 2018; Dionisio, 2019), e no campo prático geralmente surge em contextos turbulentos, principalmente em ambientes com crises sociais e ambientais.

Há o entendimento de que o empreendedorismo social é uma atividade inovadora e possui uma forte relação com a inovação social (Lubberink, et al., 2018; Phillips, Lee, Ghobadian, O’Regan, \& James, 2015). Essa inovação, embora possua um conceito amplo e abrangente, "visa satisfazer novas necessidades não atendidas pelo mercado ou criar novas formas e mais satisfatórias de dar às pessoas um lugar e um papel na vida econômica e social" (Westwood, 2009, p. 43). O seu corpo de literatura vem aumentando consideravelmente ao longo do tempo, mas ainda se encontra em estágio inicial (Caroli, Fracassi, Maiolini, Carnini \& Pulino, 2018).

Apesar do conhecimento sobre empreendedorismo social e inovação social estarem em estágios diferentes, possuem pontos em comum. Além disso, embora pesquisas sobre empreendedorismo social já estejam em fases mais avançadas, lacunas ainda persistem (Lubberink et al., 2018; Hota; Subramanian \& Narayanamurthy, 2019), pois a literatura se mantém fragmentada, (Macke et al., 2018), desarticulada e díspar devido ao seu conjunto de definições e perspectivas (Zahra, Gedajlovic, Neubaum \& Shulman, 2009). Em convergência, os estudos de inovação social também permanecem relativamente subpesquisada (Phillips et al., 2015), carecendo de mais pesquisas para que possam se desenvolver com maior celeridade (Lettice \& Parekh, 2010; Dawson \& Daniel, 2010).

Tais áreas de pesquisas vêm sendo consideradas como um meio de superar a pobreza, as mazelas, as desigualdades sociais, a falta de acesso à saúde, à educação e à habitação (Cunha \& Benneworth, 2014; Medeiros, Machado, Pereira, Costa \& Gomez, 2017), pois são mecanismos baseados no mercado que de uma forma geral promovem resultados positivos para as comunidades ou grupos de partes interessadas (Phillips et al., 2015)

Assim, notando-se a relevância da atuação prática dessas temáticas, bem como o interesse renovado por parte dos pesquisadores pelos conceitos de inovação social e empreendedorismo social (Cunha \& Benneworth, 2014), constatou-se que existem lacunas significativas quando investigadas conjuntamente. Tanto é que Phillips et al. (2015) destacam a necessidade de estudos que contemplem conjuntamente o empreendedorismo social e a inovação social, no intento de desenvolver uma compreensão compartilhada da relação conceitual entre eles. Assim, compreender os limites, a extensão e as relações entre essas temáticas se tornam cada vez mais importante para que elas evoluam (Lortie \& Cox, 2018).

Percebendo a necessidade de fazer uma distinção clara entre os dois conceitos (Cunha \& Benneworth, 2014; Lubberink et al., 2018), de mapear suas iniciativas e definições de forma distinta e de compreender a relação conceitual entre elas (Macke et al., 2018), definiu-se a seguinte pergunta de pesquisa: Como se caracterizam as relações conceituais entre o empreendedorismo social e a inovação social? Em função dessa problemática, o propósito não é focar no desenvolvimento de um conceito ou fornecer uma definição clara dos limites e da distinção entre o empreendedorismo social e da inovação social, mas sim compreender as relações conceituais existentes entre essas duas temáticas. 
A partir da delimitação dessa pergunta de pesquisa, as descobertas deste estudo propõem-se contribuir para a literatura de pelo menos três maneiras. A primeira contribuição é de fornecer informações úteis da importância de relacionar essas duas temáticas tão relevantes e emergentes para o campo teórico e prático. A segunda está associada à identificação de duas perspectivas que caracterizam às percepções de pesquisadores quanto à relação entre empreendedorismo social e inovação social, permitindo a elaboração de duas proposições de pesquisas. Finalmente, a terceira compreende a proposição de estudos futuros que podem ser operacionalizados para a difusão do conhecimento sobre esses temas.

Quanto à estrutura do artigo, após a introdução, iniciou-se a explicação sobre o empreendedorismo social e, posteriormente, a inovação social, dando prosseguimento a explanação das revisões teóricas já realizadas sobre as duas temáticas. Em seguida, apresentou-se os procedimentos metodológicos do estudo. Após isso, uma análise descritiva no intento de mapear a literatura em comento, finalizando a análise com a apresentação das perspectivas identificadas. Por fim, são apresentadas as considerações finais, destacando as limitações e novas oportunidades de pesquisa.

\section{Empreendedorismo Social}

O empreendedorismo social é considerado um subcampo do empreendedorismo e vem sendo estudado com mais tenacidade há três décadas e mesmo com alguns anos de estudos, ainda não se chegou há um consenso conceitual sobre esse fenômeno (Austin, Stevenson \& Wei-Sklilern, 2006; Thompson, 2008; Choi \& Mamjudar, 2014; Tracey \& Scott, 2017; Lubberink et al., 2018; Macke et al., 2018). Isso deve-se particularmente a multidisciplinaridade do termo, pois advém de distintas áreas e campos como sociologia, economia, ética e empreendedorismo (Saebi, Foss \& Linder, 2019).

Austin, Stevenson e Wei-Sklilern (2006, p. 2, tradução nossa), entendem que o conceito de empreendedorismo social é amplo, já que o definem "como uma atividade inovadora, criadora de valor social que pode ocorrer dentro ou entre os setores sem fins lucrativos, empresariais ou governamentais". Com base nesse conceito, depreende-se que esse fenômeno não é restritivo ao campo dos negócios sem fins lucrativos, ultrapassando, portanto, outros tipos organizacionais. Nesse sentido, Dees (1998) Dacin, Dacin e Tracey (2011) e Thompson (2008) defendem que o empreendedorismo social abrange vários domínios, como os estudos empresariais, inovação social e gestão sem fins lucrativos, não se limitando somente ao empreendedor social ou à empresa social.

Cabe destacar que o conceito de empreendedorismo social parte do pressuposto da combinação do valor social com o valor econômico, pois é a partir desse tipo de empreendedorismo que se permite desenvolver modelos inovadores para resolver os impasses da sociedade (Mair \& Marti, 2006; Macke $e t$ al., 2018; Dwivedi \& Weerawardena, 2018; Mirvis \& Googins, 2018). Nesse sentido, o empreendedorismo social não é considerado apenas a replicação de algo já existente, mas também a criação de algo novo, tratando de um problema social, com uma estrutura organizada, com foco na mobilização de recursos necessários para solucionar tal problema. Assim, o que move essa atividade não é a riqueza, mas o problema a ser solucionado, isto é, a riqueza é apenas o meio para concretizar o objetivo (Austin, Stevenson \& Wei-Sklilern, 2006).

Cabe, portanto, destacar que há uma diversidade de conceitos e definições que permeiam a área de empreendedorismo social, cada um com enfoques diferentes, como exemplo, existem autores que enfatizam a criação de valor social (Austin, Stevenson \& Wei-Sklilern, 2006), enquanto outros a inovação social (Dees, 1998; Mair \& Marti, 2006; Dacin, Dacin \& Tracey, 2011), ainda há aqueles que referenciam o conceito às atividades inovadoras (Nicholls, 2006; Austin, Stevenson \& Wei-Sklilern, 2006) e outros ao empreendedor social (Westley \& Andaze, 2010; Cunha \& Benneworth, 2014).

Em virtude disso, Choi e Mamjudar (2014) propõem uma definição que engloba as principais nuances desse fenômeno: a criação de valor social, a orientação ao mercado, a estrutura organizacional, o empreendedor social e a inovação social. Além dessa definição, há a de Nicholls (2006, p. 23, tradução 
nossa) que define esse campo como: "atividades inovadoras e eficazes que se concentram na resolução social e na criação de oportunidades para agregar valor social sistematicamente usando uma variedade de formatos organizacionais para maximizar o impacto social” (Nicholls, 2006, p.23, tradução nossa).

Assim, embora existindo diversidade de conceitos, sinaliza-se que a missão social é o enfoque central (Dees, 1998; Zahra et al., 2009; Marshall, 2011; Sassmannshausen \& Volkmann, 2013; Macke et al., 2018), de tal modo que interfere no papel do empreendedor social, sobretudo, na maneira como ele vê e analisa as oportunidades, isto é, na forma que direciona suas tomadas de decisões (Dees, 1998). Austin, Stevenson e Wei-Sklilern (2006) compreendem que o empreendedor social enfrenta constantemente pressões institucionais, sendo que essas imposições podem oscilar em relação ao contexto em que estão imersas, estimulando a introdução de inovações sociais e a condução em lidar com diversas mudanças para o desenvolvimento desse setor.

\section{Inovação Social}

As mudanças ocorridas ao longo do tempo e a forma como a sociedade se encontra atualmente estão relacionadas, em partes, com as inovações desenvolvidas. Com isso, ressalta-se que foi um processo, resultado de ações de durante anos que culminou no acesso a avançadas tecnologias devido à curiosidade humana e a difusão do conhecimento (Cajaíba-Santana, 2014). No entanto, foi somente a partir dos estudos de Schumpeter (1985), que a inovação se tornou um relevante elemento para o desenvolvimento econômico e tecnológico.

A inovação não é um termo restrito apenas ao âmbito corporativo, pelo contrário, existem outros tipos de inovação, como a artística, a educacional, a de negócios, a disruptiva, a inovação social e outras (Pol \& Ville, 2009). Como foco do presente artigo, há indícios de que a inovação social surgiu porque a inovação convencional não foi capaz de atender a todos, deixando de contemplar as comunidades e os indivíduos mais carentes. Pode-se ainda complementar, que o ambiente dos negócios tradicionais, da competitividade, da inovação tradicional e tecnológica desvirtuou-se em alguns momentos da consciência social, não buscando um equilíbrio entre o valor social e o valor econômico (Dawson \& Daniel, 2010).

Diante disso, as questões sociais foram se fortalecendo, após o reconhecimento das fraquezas e fracassos dos paradigmas empresariais convencionais (Philips et al., 2015) e, dessa forma, foi preciso desafiar o status quo, quebrar padrões para que as áreas que tratam das demandas sociais se desenvolvessem, incluindo nessa esfera, a inovação social (Lettice \& Parekh, 2010; Rao-Nicholson, Vorley \& Khan, 2018).

Assim, antes de abordar particularmente sobre a inovação social, cabe resgatar as distinções entre tal inovação e a inovação tradicional, uma vez que discussões conceituais são apresentadas entre elas (Dawson \& Daniel, 2010). Nesse sentido, a inovação tradicional é usualmente direcionada ao lucro (Mulgan, 2006; Pol \& Ville, 2009; Lettice \& Parekh, 2010) e ao ganho econômico (Schumpeter, 1985), enquanto que a inovação social está voltada ao bem-estar da sociedade (Dawson \& Daniel, 2010; Lettice \& Parekh, 2010; Phillips, Alexander \& Lee, 2018), especialmente aos marginalizados (Tan, Williams \& Tan, 2005; Bhatt \& Altinay, 2013).

Além dessas, Bignetti (2011) contempla outras divergências, ressaltando que enquanto a inovação social cria valor social, está voltada para comunidades, grupos sociais ou para toda a coletividade e tem como principal objetivo a cooperação entre os atores em torno das questões sociais, a inovação tradicional, por sua vez, está voltada ao auto interesse e ao lucro, tendo como objetivo a vantagem competitiva, com lócus exclusivo à organização, detendo altos investimentos em pesquisa e desenvolvimento (P\&D).

Outra distinção é apontada quanto ao elemento técnico, uma vez que a inovação social pode estar relacionada à criação de novas práticas sociais (Cajaíba-Santana, 2014), no qual o foco está na cultura e nos valores, com maior ênfase na dimensão humana (Murray; Mulgan; Caulier-Grice, 2010), enquanto que a inovação tradicional, geralmente está associada a uma mudança tecnológica a fim de criar novos 
produtos, serviços ou processos (Cajaíba-Santana, 2014), observando-se uma predominância na disseminação de redes e infraestruturas globais (Murray; Mulgan; Caulier-Grice, 2010). Portanto, a inovação social possui estratégias, objetivos, processos de desenvolvimento distintos da inovação tradicional, do qual exige-se modelos diferentes do convencional (Bignetti, 2011).

Logo, a partir da distinção entre inovação tradicional e inovação social, cabe definir a inovação social, pois embora não haja um consenso na literatura e nem muito menos um debate profundamente estabelecido (Caroli et al., 2018), é necessário seguir uma linha coerente conceitual. Com isso, sinaliza-se que inovação social consiste em "uma solução inovadora para um problema social mais eficaz, eficiente, ou mais do que as soluções existentes e para as quais o valor criado é principalmente para a sociedade como um todo, ao invés de particulares" (Phills, Deiglmeier \& Miller, 2008, p. 36, tradução nossa).

A inovação social surge para solucionar problemas sociais e/ou ambientais a partir da criação de produtos e processos, visualizando oportunidades com as falhas de mercado (Nicholls \& Murdock, 2012). Outro entendimento é a melhoria na qualidade de vida da sociedade como um todo (Phills, Deiglmeier \& Miller, 2008) ou de comunidades particulares (Pol \& Ville, 2009), resultando na criação de impacto social (Vo, Christie \& Rohanna, 2016). Esse impacto é justamente o resultado em termos quantitativos de pessoas beneficiadas pela inovação social. Ou seja, a partir de um método de mensuração, o resultado da criação de um produto ou serviço que atende necessidades sociais pode ser visualizado (Johnson \& Lee, 2013).

A criação do impacto social pode mudar a vida de inúmeras pessoas, promovendo qualidade de vida, saúde, educação a baixo custo, moradia, créditos financeiros, de tal modo que as pessoas passam a ter oportunidade de desfrutar de serviços de qualidade, geralmente básicos, que antes não teriam acesso. No entanto, esse impacto vai tomando proporções diferentes, inicialmente com pequena escala para posteriormente se dimensionar, isto é, atingir mais pessoas.

Cabe destacar que existem centros pioneiros voltados ao campo, criado para debater assuntos pertinentes a essa inovação e também para aproximar os praticantes dos pesquisadores, fortalecendo a área. $\mathrm{O}$ primeiro centro universitário foi o chamado Centre de recherche sur les innovations sociales (CRISES), criado no Canadá entre 1986 e 1988, que se concentra nas investigações sobre economia social, reunindo 60 pesquisadores. O segundo centro é conhecido por ZSI (Zentrum fur Soziale Innovation), criado na Àustria em meados de 1990, que desempenha diversas atividades que dizem respeito à pesquisa, ciência, política, educação e consultoria. O terceiro é o NESTA (National Endowment for Science Technology and the Arts), sediado na Inglaterra e fundado em 1998, que tem como propósito criar serviços inovadores para sociedade. O Brasil também possui um centro de inovação social em Florianópolis, denominado CAIS (Centro de Apoio à Inovação Social), criado em 2014 e voltado para o empreendedor social (Juliani, Juliani, Souza, \& Harger, 2014).

Portanto, a partir de tais considerações sinaliza um campo de conhecimento tanto em termos teóricos quanto práticos, já notando uma evolução nos últimos quarenta anos e com uma longa trajetória a ser percorrida, uma vez que nota-se frequente a preocupação das organizações, dos movimentos, grupos e indivíduos, bem como dos pesquisadores em desenvolver temáticas voltadas à transformação positiva na vida das pessoas.

\section{Revisões sistemáticas sobre as relações entre empreendedorismo social e inovação social}

Apesar de ainda escassas, revisões sistemáticas já foram realizadas anteriormente sobre as duas temáticas de forma conjunta, como as de Shaw e Bruin (2013), Cunha e Benneworth (2014), Phillips et al. (2015), Medeitos et al. (2017) e Justen, Teixeira e Segatto (2018).

A partir de uma revisão sistemática da literatura, Shaw e Bruin (2013) entendem o empreendedorismo social e a inovação social como campos de pesquisa em crescimento, em que são bastante discutidos e 
que possuem pontos em comuns. Tal estudo possui um enfoque maior na empresa social e não se percebe discussão mais ampla envolvendo a inovação social, contemplando apenas uma revisão sucinta de um editorial sobre essas duas áreas em estudo. A sua principal contribuição reside nas sugestões de pesquisas futuras e na discussão realizada entre empresa social, empreendedorismo social e inovação social.

Cunha e Benneworth (2014), em estudo revisional faz distinção entre inovação social e empreendedorismo social, traçando os limites de cada um desses conceitos. Inicialmente, retrata que a inovação social, diferentemente do empreendedorismo social, transcende níveis de análise e métodos, sendo, portanto, mais amplo. Já o empreendedorismo social é representado, na maioria das vezes pelo empreendedor social que nem sempre cria modelos inovadores. Adicionalmente, embora haja divergências, os autores apresentaram alguns pontos em comuns, tais como: inovação, criação de valor social, empreendedor social e o surgimento dessas duas áreas como resultado da incapacidade do governo em satisfazer as necessidades sociais.

Phillips et al. (2015) ao elaborar uma revisão sistemática da literatura sobre empreendedorismo social e inovação social que cobriu até ano de 2012, identificou temáticas convergentes, desvelando as similaridades que permeiam essas duas áreas, mostrando que ambas surgiram com o intuito de identificar e solucionar problemas sociais. Além disso, relataram que os estudos que envolvem o empreendedorismo social e a inovação social vem crescendo nos últimos cinco anos, com tendência de crescimento. Adicionalmente, foi possível observar que como o objetivo era estabelecer apontamentos em comuns entre essas duas temáticas, em alguns momentos não ficou tão esclarecedor se realmente os autores cumpriram com a proposta definida, sobretudo por não terem buscado os termos de forma conjunta nas bases de dados, bem como pelas explicações descritas na análise.

Medeiros et al. (2017) realizou um levantamento de trabalhos apresentados sobre os conceitos de inovação social e empreendedorismo social, considerando as possíveis intersecções entre estes e conexões com a lógica da economia solidária. Utilizaram como base apenas trabalhos da ANPAD entre os anos 2008 e 2015. Além da utilização da base da ANPAD, realizaram entrevistas com alguns autores dos estudos selecionados no intento de esclarecer alguns pontos. Como resultado, identificaram que ainda há poucos estudos sobre empreendedorismo social e inovação social no âmbito e que o conceito da primeira área está mais definido, por ser mais concreto e por estar voltado à uma organização física e ao empreendedor social.

Justen, Teixeira e Segatto (2018) identificaram os elementos de convergências e diferenciação entre os conceitos de empreendedorismo social e inovação social e como resultado, apresentaram que apesar das divergências motivacionais, em que o primeiro pretende atender uma falha de mercado e o segundo uma falha do sistema, possuem pontos comuns como a criação de valor social e a geração de mudanças na sociedade voltados para a solução de problemas sociais.

O presente estudo se diferencia dos demais por não ter tido foco específico na empresa social, assim como teve o de Shaw e de Bruin (2013), bem como não se pretendia identificar as divergências e convergências como o de Cunha e Benneworth (2014) e Justen, Teixeira e Segatto (2018) e não identificou-se somente as temáticas em comuns entre o empreendedorismo social e a inovação social como o de Phillips et al. (2015), mas sim tentou-se compreender as relações conceituais existentes entre essas duas temáticas, a partir de uma pesquisa revisional. Nesse sentido, após o desenvolvimento do arcabouço teórico, explicou-se, na seção seguinte, os procedimentos metodológicos empregados para realização da revisão.

\section{Procedimentos metodológicos}

Para atender aos objetivos da pesquisa, realizou-se uma revisão sistemática da literatura que compreende a avaliação de um conjunto de dados simultâneos no intento de obter provas científicas por meio de uma exaustiva busca na literatura (Atallah \& Castro, 1998; Tranfield, Denyer \& Smart, 2003; Denyer \& 
Tranfield, 2009). A partir desse método se obtém um desenvolvimento qualitativo do corpo de literatura relevante, realizando um processo de pesquisa documentado, replicável e transparente (Bouncken, Gast, Kraus \& Bogers, 2015). A operacionalização desse método reside na identificação de estudos disponibilizados em periódicos e bases de dados sobre áreas específicas no intento de responder a um problema de pesquisa (Sampaio \& Mancini, 2007).

Após a definição do problema norteador dessa revisão, identificou-se publicações relevantes sobre empreendedorismo social e inovação social de forma conjunta. A identificação dessas pesquisas, iniciouse a partir da escolha das bases de dados internacionais e nacionais. A base escolhida foi Scopus, por ser referência internacional e pela sua abrangência, utilizando os termos de busca "social entrepreneurship" AND "social innovation", sem restrição de datas. A nacional foi a Spell, principal base brasileira, empregando os termos "empreendedorismo social" e "inovação social", sem data de restrição. É válido ressaltar que as aspas foram utilizadas no intento de garantir que os termos fossem encontrados na mesma ordem, fornecendo resultados mais específicos.

Após essas definições, realizou-se a primeira busca na Scopus, empregando os seguintes filtros: 'keyword', 'business, management and accounting' e 'article', finalizando com 58 trabalhos. Na fase de seleção dos artigos nacionais, iniciou-se a busca na Spell, utilizando apenas 'resumo' como filtro, identificando 31 artigos. Contudo, ao ler os resumos dos trabalhos, somente dois deles tratavam do empreendedorismo social e da inovação social conjuntamente sem, no entanto, trazer contribuições aprofundadas acerca do problema de pesquisa delimitado no presente estudo, optando-se, desse modo, por não incluir a base de dados brasileira na análise.

Ao selecionar os 58 artigos, delimitou-se critérios de inclusão e exclusão no intuito de escolher somente aqueles consistentes com o escopo e o objetivo estabelecido anteriormente.

Com isso, o desenvolvimento de três critérios específicos para inclusão e exclusão de artigos fizeram parte desta etapa, quais sejam: i) somente artigos científicos publicados em periódicos; ii) estudos que tenham como foco o empreendedorismo social e a inovação social tratadas conjuntamente, eliminando os falsos positivos que aparecem apenas algumas vezes no texto sem ser o cerne do trabalho e; iii) estudos que atendem aos critérios de qualidade, rigor e confiabilidade de uma pesquisa. Os trabalhos que não atenderam esses critérios foram apresentados na Figura 1.

\begin{tabular}{|c|c|c|}
\hline Critério de inclusão & Descrição & Trabalhos excluídos \\
\hline $\begin{array}{l}\text { Estudos sobre } \\
\text { empreendedorismo } \\
\text { social e inovação } \\
\text { social de forma } \\
\text { conjunta }\end{array}$ & $\begin{array}{l}\text { Os estudos deveriam tratar } \\
\text { diretamente da relação entre } \\
\text { o empreendedorismo social } \\
\text { e inovação social } \\
\text { conjuntamente }\end{array}$ & $\begin{array}{l}\text { Aquino, Viagem, Schänzel (2018); Caroli, Fracassi, Maiolini, } \\
\text { Carnini Pulino(2018); Dwivedi, Weerawardena (2018); } \\
\text { Macke, Sarate, Domeneghini, Silva (2018); Mirvis, Googins } \\
\text { (2018); Popov(2018); Newth (2018); Spiegler e Halberstadt } \\
\text { (2018); Stott, Tracey (2018); Roundy e Bonnal (2017); } \\
\text { Turker e Vural(2017); Sabato, Vanhercke, Verschraegen } \\
\text { (2017); Suzana, Zulazli e Zainudin (2017); } \\
\text { Kuratko, McMullen, Hornsby, Jackson (2017); Bjärsholm } \\
\text { (2017); Misener e Misener (2017); Goyal, Sergi e Kapoor } \\
\text { (2017); Sandeep e Ravishankar (2015); Rivers, Nie } \\
\text { e Armellini (2015); Méndez-Picazo, Ribeiro-Soriano e } \\
\text { Galindo-Martín (2015); Bruin e Lewis (2015); Borzaga e } \\
\text { Galera (2014); Păunescu (2014); Germak e Robinson (2014); } \\
\text { Chalmers e Balan-Vnuk (2013); Godói-de-Sousa e Júnior } \\
\text { (2013), Sundaramurthy, Musteen e Randel (2013); Maak e } \\
\text { Stoetter (2012); Dees (2012); Holweg e Lienbacher (2011); } \\
\text { Lehner (2011); Witkamp, Royakkers e Raven (2011); Perrini, } \\
\text { Vurro e Costanzo (2010); Dawson e Daniel (2010). }\end{array}$ \\
\hline
\end{tabular}

Figura 1. Artigos excluídos

Fonte: Elaborada pelas autoras (2018) 
Após definidos os critérios, os artigos passaram por uma avaliação específica do resumo, da introdução e da metodologia, identificando-se que dos 58 artigos selecionados na etapa anterior, apenas 21 se alinhavam ao critério estabelecido, já assegurado que possuem relação entre o empreendedorismo social e a inovação social.

Os 21 artigos foram lidos e cuidadosamente relidos no intento de codificar as características dos estudos e seus principais insights. Além dos dados gerais, como título, autor (es), ano de publicação e periódico, também foram extraídos dos artigos, o objetivo geral, a referências teóricas de inovação social e empreendedorismo social, as escolhas metodológicas e principais conclusões.

Após a síntese realizada individualmente de cada artigo, tentou-se identificar as relações conceituais existentes entre o empreendedorismo social e a inovação social. Assim, a partir dessa intenção, a análise foi dividida em duas etapas: análise descritiva (temporal, principais periódicos, temática, países e metodológica (teórico, empírico, qualitativo ou quantitativo) e análise das relações conceituais.

As relações conceituais identificadas emergiram durante a análise dos artigos, uma vez que a partir das leituras foi possível perceber que haviam dois entendimentos quanto ao posicionamento dos autores perante à relação entre o empreendedorismo social e a inovação social, conforme pode ser visualizado na seção de análise.

\section{Apresentação e análise dos resultados}

\section{Análise descritiva}

A análise descritiva foi elaborada a partir dos 21 artigos selecionados na base da Scopus, que apresentaram relação direta entre o empreendedorismo social e a inovação social de forma conjunta. Nesse sentido, realizou-se as seguintes descrições: temporal, principais periódicos, temáticas dos estudos e questões metodológicas.

Os artigos foram categorizados de acordo com as publicações por ano. Notou-se, a partir da Figura 2, que o primeiro estudo, envolvendo essas duas temáticas conjuntamente, segundo a base pesquisada, foi publicado em 2010. Cabe destacar que entre 2010 e 2012 a relação entre essas duas temáticas foi pouca representativa, considerando que os estudos de inovação social e de empreendedorismo social começaram a entrar em ascensão a partir de 2006, como o de Mulgan (2006) sobre inovação social e o de Mair e Marti (2006) sobre empreendedorismo social. Constata-se ainda que 2017 foi o ano com maior número de publicações com oito artigos. Isso deve-se pelo próprio dimensionamento da área no campo prático e o surgimento de novas empresas sociais. Embora havendo oscilações entre os anos, acredita-se que a tendência é expandir o número de trabalhos publicados nessas áreas específicas (Phillips et al., 2015).

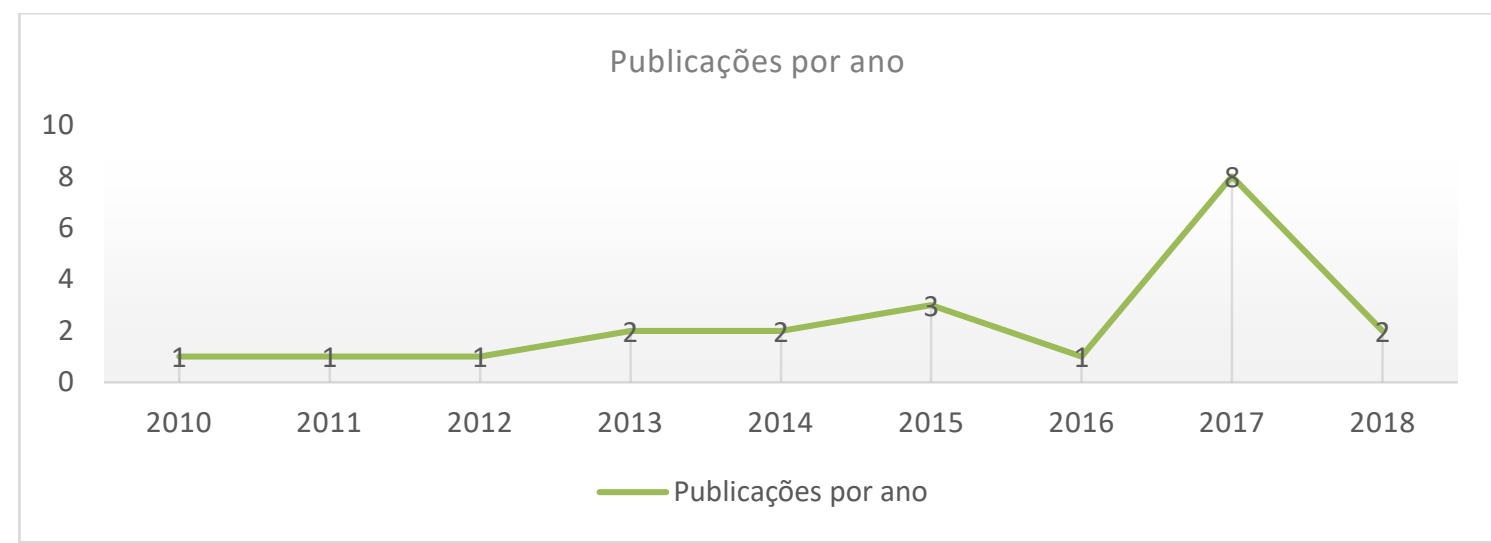

Figura 2. Quantidade de publicações sobre empreendedorismo social e inovação social por ano Fonte: Elaborada pelas autoras (2018) 
As pesquisas de empreendedorismo social e inovação social de forma conjunta foram estudadas a partir das seguintes temáticas: definições e tipologias, redes e sistemas, desafios, impacto social, patrimônio cultural, modelo de negócio, finanças, comunidades, resistência social e identidade organizacional, conforme foi apresentado na Tabela 1. Assim, é possível perceber que existe uma diferença entre as temáticas pesquisadas, principalmente se o estudo é teórico ou empírico. No caso dos estudos teóricos, se pautaram nas definições e tipologias e, enquanto os estudos empíricos tiveram como foco o impacto social, as redes e sistemas e os desafios.

$\begin{array}{ll}\begin{array}{l}\text { Tabela 1: Temáticas dos estudos } \\ \text { Temáticas }\end{array} & \text { Total de artigos } \\ \text { Definições e tipologias } & 5 \\ \text { Impacto Social } & 4 \\ \text { Redes e sistemas } & 3 \\ \text { Desafios } & 3 \\ \text { Patrimônio Cultural } & 1 \\ \text { Modelo de Negócio } & 1 \\ \text { Finanças } & 1 \\ \text { Comunidades } & 1 \\ \text { Resistência Social } & 1 \\ \text { Identidade Organizacional } & 1 \\ \text { TOTAL } & \mathbf{2 1} \\ \text { Fonte: Elaborada pelas autoras (2018) } & \end{array}$

$\mathrm{Na}$ Tabela 2 observa-se que diversos periódicos publicaram nessas áreas, com destaque para Journal of Social Entrepreneurship com quatro artigos, Voluntas e Pertanika Journal of Social Sciences and Humanities com dois artigos cada. O primeiro se justifica pelo foco do periódico está voltado ao empreendedorismo social. Esses três journals possuem os seguintes fatores de impacto: 1.63, 1.27 e 0.029, respectivamente. Cabe ainda mencionar que o Journal of Asia-Pacific Business foi o primeiro, em 2010, segundo as bases selecionadas, a publicar artigos envolvendo as duas temáticas de forma conjunta.

$\begin{array}{ll}\text { Tabela 2: Periódicos } & \text { Total de artigos } \\ \begin{array}{l}\text { Periódicos } \\ \text { Journal of Social Entrepreneurship }\end{array} & 2 \\ \text { Voluntas } & 2 \\ \text { Pertanika Journal of Social Sciences and Humanities } & 1 \\ \text { International Entrepreneurship and Management Journal } & 1 \\ \text { International Journal of Entrepreneurship and Small Business } & 1 \\ \text { International Journal of Entrepreneurial Behaviour and } & 1 \\ \text { Research } & \\ \text { Intangible Capital } & 1 \\ \text { Technological Forecasting and Social Change } & 1 \\ \text { Innovation: Management, Policy and Practice } & 1 \\ \text { Group and Organization Management } & 1 \\ \text { Human Service Organizations Management, Leadership and } & 1 \\ \text { Governance } & \\ \text { Jurnal Pengurusan } & 1 \\ \text { International Small Business Journal } & 1 \\ \text { Journal of Public Policy and Marketing } & 1 \\ \text { Technology Analysis and Strategic Management } & 1 \\ \text { Journal of Asia-Pacific Business } & 1 \\ \text { TOTAL } & 21 \\ \text { Fonte: Elaborada pelas autoras (2018) } & \end{array}$


Identificou-se ainda que os países que tem estimulado e realizado maiores contribuições relacionando o campo de empreendedorismo social e inovação social são os Estados Unidos e o Reino Unido, visto que apresentaram o maior número de artigos publicados. Além disso, esta pesquisa também investigou os aspectos metodológicos empregados nos estudos, e identificou que dos 21 trabalhos, 13 poderiam ser caracterizados como teóricos e nove empíricos. Desses últimos, um possuía abordagem mista (Quali/Quanti), um possuía abordagem quantitativa e sete eram qualitativos, sendo o estudo de caso a estratégia de pesquisa utilizada.

\section{Análise das relações conceituais entre empreendedorismo social e inovação social}

Esta subseção caracteriza as duas relações conceituais identificadas entre empreendedorismo social e inovação social: i) empreendedorismo social como uma inovação social e ii) empreendedorismo social como gerador de inovação social.

\section{Empreendedorismo social como uma inovação social}

Alguns autores como Grohs e Schneiders e Heinze (2017), Tracey e Scott (2017), Alexandre-Leclair (2017), Phillips et al. (2015), Mueller et al. (2015) e Witkamp, Raven e Royakkers (2011) entendem a relação conceitual entre o empreendedorismo social e a inovação social como sobrepostas, no sentido de que o empreendedorismo social é uma inovação social, sendo este último mais amplo e abrangente e o empreendedorismo social uma atividade inovadora mais específica.

No intento de detalhar a percepção desses autores, inicia-se com Grohs, Schneiders e Heinze (2017) e Witkamp, Raven e Royakkers (2011) que argumentam que o próprio empreendedorismo social pode ser uma atividade de inovação social, ao invés de uma forma organizacional específica. Ou seja, os empreendedores sociais são considerados incubadores de inovação, nos quais esses atores possuem o papel principal nessa relação.

Tracey e Scott (2017) complementam que a inovação social pode ser considerada um conceito abrangente, incorporando diversas atividades, entre elas, a do empreendedorismo social. Inclusive, conceituaram inovação social como uma forma de gerenciar organizações, maximizar a aquisição de recursos e inibir as desigualdades, bem como desenvolver um espírito altruísta do empreendedor social e daqueles que estão a sua volta para solucionar problemas e desafios intratáveis do mundo. Nesse sentido, desvelam que o empreendedorismo social e a inovação social possuem conceitos que se complementam, visto que ambos destacam a relevância de se trabalhar com redes, cooperações no intento de facilitar a criação de soluções, como também desenvolver ecossistemas voltados para a mudança social. Além disso, ambos estão inseridos em ambientes que facilitam as combinações de ideias, pessoas e lugares para enfrentar as disfunções socioambientais. Esses autores ainda destacam que a tecnologia digital está sendo um meio de unir esses dois fenômenos, pois as inovações sociais e o empreendedorismo social estão ganhando tração por meio dessa ferramenta.

Alexandre-Leclair (2017) apresenta entendimento convergente dos demais, compreendendo o empreendedorismo social como uma solução que preenche um vazio não atendido pelo poder público ou por empreendedores convencionais, sendo que normalmente essa solução é considerada uma inovação social. Também destaca que a maior parte dos conceitos de empreendedorismo social englobam a inovação ou a inovação social como parte central. Para fundamentar tal entendimento citam a referência de Mair e Marti (2006), constatando que é como se o empreendedorismo social estivesse dentro do sistema de inovação social.

O conceito de empreendedorismo social adotado por Alexandre-Leclair (2017) é a criação de qualquer atividade com objetivo social e sustentável, que tenha a busca de lucro ou não, utilizando-se da inovação social como meio de potencializar a geração de impacto, empregando programas participativos de governança para atingir seu objetivo. Alexandre-Leclair (2017) e Jäger e Schröer (2014) compreendem a 
inovação social como um pilar para o empreendedorismo social. Inclusive, Jäger e Schröer (2014) tratam esses fenômenos como unívocos, tendo em vista que o caso analisado de empreendedorismo social era caracterizado como uma inovação social.

Phillips et al. (2015) ao elaborar uma revisão sistemática da literatura identificam alguns assuntos em comum em relação a essas duas temáticas, tais como o papel do empreendedor, redes e sistemas, a formação dos colaboradores, o desenvolvimento de parcerias institucionais e o importante papel das instituições. No entanto, observou-se a partir desse estudo, a dificuldade em traçar limites quanto às temáticas que os envolvem, pois por buscarem a criação de valor social, como também atender necessidades sociais ainda não compreendidas pelo poder público ou por outras iniciativas, se sobrepõem em diversos aspectos. Embora a semelhança de assuntos em comuns e ambos almejarem a mudança social, o que os diferencia é que o empreendedorismo social possui uma visão mais solitária, enquanto a que a inovação social depende de uma interação conjunta e coletiva. Mas mesmo com essa consideração, chegam a conclusão de que o empreendedorismo social existe dentro de um sistema de inovação social no intento de auxiliar a moldar a cultura da sociedade.

Por sua vez, Mueller et al. (2015), Phillips et al. (2015) e Munshi (2010) constataram que as dificuldades de evolução da literatura sobre empreendedorismo social são decorrentes à falta de conhecimento sobre inovação social. Inclusive, Munshi (2010) apontou que para aumentar o conhecimento sobre empreendedorismo social é necessário compreender esse tipo de inovação, pois o empreendedorismo social é percebido como uma inovação social radical em nível de sistema provocada por inovadores sociais que estão especificamente interessados em resolver questões sociais mais amplas. A partir desse conhecimento é possível conectar o empreendedorismo social com outras áreas e domínios como a política social, inovação tecnológica e a resolução de problemas. Assim, é preciso aplicar e reter esses conhecimentos para que alcance os principais objetivos sociais (Mueller et al., 2015; Phillips et al., 2015) e tenha um avanço no campo.

Ademais, Mueller et al. (2015) e Mushi (2010) ressaltam que a própria prática do empreendedorismo social são atos de inovação social, pois a ação de empreender socialmente é uma atividade inovadora que promove benefícios mútuos à sociedade de um modo mais radical quando comparada apenas a criação de um produto e/ou serviço.

Portanto, a partir das descrições dos estudos, elaborou-se a Figura 3 que apresenta os artigos e os autores correspondentes à perspectiva conceitual em que o empreendedorismo social é visto como uma inovação social.

\begin{tabular}{|c|c|}
\hline & \\
\hline neiders e & $\begin{array}{l}\text { Outsiders and Intrapreneurs: The Institutional Embeddedness of Social } \\
\text { Entrepreneurship in Germany }\end{array}$ \\
\hline Tra & a window on alternative ways of organizing and innovating \\
\hline Alexand & $\begin{array}{l}\text { as a tool of women social } \\
\text { n: The case of the Sougha }\end{array}$ \\
\hline & Social Entrenreneurship: A Systematic Review \\
\hline Mueller et al. (2015) & the Impediments \\
\hline Jäger e Schröer (2014) & $\begin{array}{l}\text { Integrated Organizational Identity: A Definition of Hybrid Organizations } \\
\text { and a Research Agenda }\end{array}$ \\
\hline $\begin{array}{l}\text { Witkamp, Raven } \\
\text { Royakkers (2011) }\end{array}$ & $\begin{array}{l}\text { Strategic niche management of social innovations: The case of social } \\
\text { entrepreneurship }\end{array}$ \\
\hline Munshi (2010) & on, and entrepreneurship in global economies \\
\hline
\end{tabular}

Figura 3. O empreendedorismo social visto como uma inovação social

Fonte: Elaborada pelas autoras (2018) 
Assim, a partir das colocações e percepções desses autores, elaborou-se a seguinte proposição de pesquisa:

Proposição 1: O empreendedorismo social é caracterizado como uma inovação social por ser uma atividade que busca atender de forma inovadora as necessidades sociais.

\section{Empreendedorismo social como gerador de inovação social}

Autores como Lortie e Cox (2018), Rao-Nicholson, Vorley e Khan (2018), Lubberink et al. (2018), Nandan, Londres e Bent-Goodley (2015), Zainudin, Raja Suzana e Zulazli (2017), Zulazli, Raja Suzana, Zainudin, Abang Feizal \& Mokhtarrudin (2017), Thoene e Turriago-Hoyos (2017) Zebryte e Jorquera (2017), Toivoven (2016), Newth e Woods (2014), Muhamad e Adham (2013) e Shaw e Bruin (2013) percebem a relação conceitual entre o empreendedorismo social e a inovação social como diferentes, mas entendem que possuem interseções que facilitam e potencializam a geração de valor social. Assim, são a partir dessas relações que o empreendedorismo social é considerado um meio propício para promover e estimular a geração de inovação social.

Pesquisadores entendem que há uma forte conexão entre esses dois campos de pesquisa, porque o empreendedor social pode por meio da sua ação gerar inovações nos seus modelos de negócios, bem como criar produtos e/ou serviços que satisfaçam as necessidades humanas que ainda não foram atendidas, mudem as relações sociais existentes e capacitem aqueles que não possuem condições para isso (Lortie \& Cox, 2018; Lubberink et al., 2018; Nandan, Londres \& Bent-Goodley, 2015). Ou seja, a inovação social contribui para o sucesso do empreendedorismo social (Zainudin, Raja Suzana \& Zulazli, 2017) e vice-versa.

Compreendendo o papel do empreendedor social, Lubberink et al. (2018) destacaram que o empreendedorismo social pode de fato se tornar inovador quando transforma ideias em soluções visionárias que atendem necessidade sociais. Ou seja, essa relação é positiva no sentido de que a aplicabilidade da inovação social pelo empreendedor social gera novas ideias que reduzam as disfunções socioambientais (Lortie \& Cox, 2018; Lubberink et al., 2018; Newth \& Woods, 2014). Lubberink et al. (2018), ao finalizarem suas considerações, entendem que duas teorias podem explicar o comportamento de empreendedores sociais ao desenvolver inovação sociais, a primeira delas é a bricolagem e a segunda é a teoria da effectuation.

Os estudos de Zulazli et al. (2017) e Nandan, Londres e Bent-Goodley (2015) corroboram tais entendimentos e ainda complementam que a inovação social promove impacto a longo prazo para o empreendedorismo social. Ou seja, os empreendedores sociais usam a inovação para criar valor social e mudança social por meio de um produto e/ou serviço seja no setor público, privado ou sem fins lucrativos (Zulazli et al., 2017; Nandan, Londres \& Bent-Goodley, 2015). Portanto, o empreendedorismo social prioriza a inovação social e a responsabilidade para com a sociedade (Muhamad \& Adham, 2013).

No entanto, os autores consideram o empreendedorismo social e a inovação social como abordagens diferentes (Lortie \& Cox, 2018; Lubberlink et al., 2018; Thoene \& Turriago-Hoyos, 2017; Shaw \& Bruin, 2014), pois não dependem um do outro. Thoene e Turriago-Hoyos (2017) identificaram uma quantidade considerável de estudos sobre inovação social que nem sequer mencionaram o termo empreendedorismo social, como também estudos sobre empreendedorismo social, em que a inovação social não é determinante. No entanto, quando se juntam, o grupo de atores interessados tendem a ganhar pois são importantes para mobilização de recursos e para o desenvolvimento de capacidades. Nesse sentido, o empreendedorismo social não é compreendido como resultado, mas como meio da inovação social (RaoNicholson, Vorley \& Khan, 2018). 
Lubberink et al. (2018) acrescentam que, embora tenham conceitos e definições diferentes são entendidos também como complementares, devem sem conduzidas juntos para que o objetivo socioambiental seja alcançado mais facilmente. No entanto, em suas discussões deixam claro que a inovação social é mais ampla no sentido de não se limitar ao empreendedorismo social, pois pode ser gerada em diversos contextos, seja social ou não, como também possui a potencialidade em transformar sistemas sociais, e isso já não é necessariamente verdade para o empreendedorismo social.

A partir dessa perspectiva em que se entende o empreendedorismo social como promotor de inovação social, Zebryte e Jorquera (2017) sinalizam que essa relação gera empreendedores mais participativos e cooperativos e serviços e produtos inovadores. Como resultado do estudo, revelaram que a colaboração sistemática e progressiva promovida pelas inovações sociais estimula melhores resultados no que diz respeito ao impacto social do empreendedorismo social. Isso é possível, pois juntamente com empresas parceiras e universidades, se desenvolve ferramentas de inovação social que permitem promover laços com o ambiente da melhor maneira possível a fim de aprimorar os processos de gestão e treinar equipes.

Toivoven (2016) apresenta um conceito novo e ainda pouco conhecido que é o de comunidades de inovação social. Essas comunidades, impulsionadas por uma colaboração lógica comunitária, apoiam o empreendedorismo social, particularmente em estágios iniciais e contribuem para a introdução de inovações sociais. Assim, a principal relação existente entre empreendedorismo social e inovação social desencadeada por Toivoven (2016) e Nandan, Londres e Bent-Goodley (2015) é a colaboração entre os parceiros e a formação de redes.

Toivoven (2016) destaca a internet e a tecnologia como aliadas desses fenômenos em que cada vez estão sendo valorizadas, inclusive ressalta que são ferramentas importantes para que o empreendedorismo social possua mais facilidade em gerar inovações sociais. Adicionalmente, também aponta o capital social e a confiança como elementos que permeiam essas temáticas. Por fim, como resultado do estudo, o autor identificou que as comunidades de inovação social, também entendido como empreendedorismo social, são veículos que facilitam a introdução da inovação social em novos mercados culturais e configurações geográficas, bem como reforçam circuitos de inovações mais amplas.

Assim, a partir das descrições dos estudos, elaborou-se a Figura 4 que apresenta os artigos e os autores correspondentes à perspectiva em que o empreendedorismo social é visto como promotor de inovação social, ou seja, um campo propício para geração dessa inovação.

\begin{tabular}{|c|c|}
\hline Autor (es) & Título \\
\hline Lortie e Cox (2018) & $\begin{array}{l}\text { On the boundaries of social entrepreneurship: a review of relationships with } \\
\text { related research domains }\end{array}$ \\
\hline Lubberink et al. (2018) & $\begin{array}{l}\text { Innovation for Society: Towards a Typology of Developing Innovations by Social } \\
\text { Entrepreneurs }\end{array}$ \\
\hline $\begin{array}{l}\text { Rao-Nicholson, Vorley e Khan } \\
\text { (2018) }\end{array}$ & $\begin{array}{l}\text { Social innovation in emerging economies: A national systems of innovation based } \\
\text { approach }\end{array}$ \\
\hline $\begin{array}{l}\text { Zainudin, Raja Suzana, Zulazli } \\
\text { (2017) }\end{array}$ & $\begin{array}{l}\text { Modelling social innovation for young entrepreneurs living in the marginalised } \\
\text { communities in Malaysia }\end{array}$ \\
\hline Zulazli et al. (2017) & The impact of social innovation on an enterprise success: Item validation \\
\hline Zebryte e Jorquera (2017) & $\begin{array}{l}\text { Chilean tourism sector "B Corporations": evidence of social entrepreneurship and } \\
\text { innovation }\end{array}$ \\
\hline Thoene e Turriago-Hoyos (2017) & Financial inclusion in Colombia: A scoping literature review \\
\hline Toivoven (2016) & $\begin{array}{l}\text { What is the Social Innovation Community? Conceptualizing an Emergent } \\
\text { Collaborative Organization }\end{array}$ \\
\hline $\begin{array}{l}\text { Nandan, Londres e Bent- } \\
\text { Goodley (2015) }\end{array}$ & $\begin{array}{l}\text { Social Workers as Social Change Agents: Social Innovation, Social } \\
\text { Intrapreneurship, and Social Entrepreneurship }\end{array}$ \\
\hline Newth e Woods (2014) & Resistance to Social Entrepreneurship: How Context Shapes Innovation \\
\hline Weerawardena e Mort (2012) & $\begin{array}{l}\text { Competitive strategy in socially entrepreneurial nonprofit organizations: } \\
\text { Innovation and differentiation }\end{array}$ \\
\hline
\end{tabular}

Figura 4. O empreendedorismo social como gerador de inovação social

Fonte: Elaborada pelas autoras (2018) 
A partir das percepções desses autores, elaborou-se a seguinte proposição de pesquisa:

Proposição 2: O empreendedorismo social é caracterizado como um campo propício para gerar inovações sociais por meio da figura do empreendedor social.

\section{Discussão dos resultados}

A partir da análise de 21 artigos que tratavam sobre o empreendedorismo social e a inovação social conjuntamente, observou-se que pesquisas unindo esses dois campos ainda são recentes e pode ser visto como um campo de estudos emergentes, tanto é que no Brasil, identificou-se somente dois artigos teóricos indexados na Spell, principal base de dados nacional.

As principais temáticas identificadas nesses estudos são sobre tipologias e definições, impacto social, redes e sistemas e desafios. Vale destacar que estudos sobre redes e sistemas estão crescendo rapidamente, pois tanto o empreendedorismo social, como também a inovação social, utilizam dessas estratégias para disseminarem e implantarem culturas mais participativas e colaborativas no ambiente em que estão imersos. Para alcançar tal desenvolvimento, observou-se a necessidade de que as pesquisas saiam do nível puramente empírico, isto é, evitem evidências informais e alcancem estudos de casos mais aprofundados e investigações com abordagens quantitativas no intento de criar modelos capazes de contribuir teoricamente e empiricamente.

Ao se analisar as relações conceituais, foi possível identificar duas perspectivas: o empreendedorismo social visto como uma inovação social e o empreendedorismo social visto como um campo propício para geração de inovação social.

No entanto, embora percepções diferentes sejam apontadas pelos autores analisados, essas duas abordagens compreendem o empreendedor social como ator principal dessa junção, que a partir da atuação desse ator é possível a implementação de inovações sociais, como também a potencialização de criação de valor social. Portanto, o empreendedor social é uma figura importante para o funcionamento da atividade, para a motivação de outros atores envolvidos, para formação de cultura organizacional focada no valor social e/ou ambiental e para o alcance do impacto social.

Adicionalmente, independente da perspectiva adotada, a inovação social, faz parte do cerne do empreendedorismo social, visto ser uma atividade inovadora (Lortie \& Cox, 2018; Lubberlink et al., 2018; Rao-Nicholson, Vorley \& Khan, 2018; Thoene \& Turriago-Hoyos, 2017; Grohs, Schneiders \& Heinze, 2017, Tracey \& Scott, 2017, Alexandre-Leclair, 2017; Phillips et al., 2015, Mueller et al., 2015; Shaw \& Bruin, 2014; Witkamp, Raven \& Royakkers, 2011). O empreendedorismo social sendo inovador consegue alcançar mais facilmente o seu objetivo final. Para isso, a inovatividade deve ser encarada como algo cultural e deve ser central desde a fase inicial de criação dessa atividade, bem como deve estar explícita na missão e no modelo de negócio do ato de empreender. Nesse sentido, os empreendedores sociais não devem subestimar a importância da inovação como um modo de obter valor social (Srivetbodee, Igel \& Kraisornsuthasinee, 2017).

No entanto, embora o empreendedorismo social tenha seu caráter inovador, nem sempre é (Phillips et al., 2015). Ou seja, não se pode universalizar que todo empreendedorismo social é uma inovação social, pois irá depender da caracterização dessa atividade, da dimensão do problema que será solucionado e do contexto que está inserido. Como também não se pode entender exclusivamente que esse empreendedorismo sempre desenvolve produtos e serviços inovadores que satisfaçam necessidades sociais de forma sistêmica, tendo em vista que nem sempre isso acontece.

Ademais, as duas perspectivas atingem consenso ao perceber que a inovação social é mais ampla no sentido de não se limitar ao empreendedorismo social, pois essa inovação pode ser gerada em diversos 
contextos, seja social ou não, transcendendo setores e níveis de análise (Lettice \& Pareck, 2010; Dawson \& Daniel, 2010; Bigneti, 2011; Cajaiba-Santana, 2014), possibilitando transformação sistemática à sociedade.

\section{Considerações finais}

Apesar da relevância crescente dos estudos sobre empreendedorismo social e inovação social de forma isolada constatou-se que existem lacunas de pesquisa na análise das duas temáticas de forma conjunta. Este estudo pretendeu analisar as relações conceituais entre empreendedorismo social e inovação social utilizando-se a revisão sistemática de literatura como estratégia de pesquisa. Fundamentado nisso, identificou-se que a literatura envolvendo as duas terminologias conjuntamente ainda é limitada. Há indícios de que isso decorre devido às duas áreas estarem tão relacionadas que os pesquisadores as tratam de forma semelhante, como se todo ato de empreendedorismo social fosse inovador, refletindo em incoerências. Embora tais inconsistências, o empreendedorismo social é uma perspectiva interessante para o desenvolvimento de teorias sobre inovação social, e vice-versa.

A estrutura do artigo e as nuances encontradas nos estudos forneceram um ponto de partida significativo para análise mais focada na integração dos conceitos. Com isso, respondendo ao objetivo de pesquisa, identificou-se duas perspectivas que caracterizam a relação entre as temáticas estudadas: o empreendedorismo social visto como uma inovação social e o empreendedorismo social visto como um campo propício para geração de inovação social. Reunir essa literatura sobre empreendedorismo social e inovação social permitiu desenvolver essas duas proposições de pesquisa que apresentam como diferentes abordagens se relacionam teoricamente. É importante ressaltar que outras perspectivas podem ser identificadas, visto que tanto o empreendedorismo social, como também as inovações sociais assumem múltiplas formas, dependendo das circunstâncias socioeconômicas e culturais (MAIR; MARTI, 2006). Além disso, o estudo não tinha a intenção de exaurir essa discussão, mas de estimular que outros estudos com esse mesmo objetivo sejam realizados.

Verificou-se também que a pesquisa especialmente qualitativa pode se beneficiar de fundamento teórico para análise, a fim de fornecer insights mais aprofundados. Isso deve-se particularmente as temáticas terem um viés mais social, com respostas mais subjetivas e profundas conseguem informações para compreensão desses fenômenos e as suas relações sociais. No entanto, pesquisas quantitativas também são almejadas para esse contexto, a fim de se entender essas relações a partir da estatística, inclusive porque toda e qualquer pesquisa pode trazer contribuições válidas, independente da abordagem utilizada.

Dentre as principais contribuições teóricas desse estudo, destaca-se, em um primeiro momento, a identificação de duas perspectivas distintas que podem auxiliar outros pesquisadores a se situarem conceitualmente, identificando a abordagem que mais condiz com a proposta e operacionalização da sua pesquisa. Isso se torna importante pela dificuldade de pesquisadores entenderem conceitualmente as diferenças existentes entre inovação social e empreendedorismo social, sobretudo tratando-as como unívocas devido às similaridades que permeiam essas duas temáticas. Em segundo momento, a própria discussão sobre empreendedorismo social e inovação social vem a somar com os estudos existentes, tendo em vista que ainda não identificaram na literatura brasileira outras pesquisas com essa mesma proposta. Por fim, ao final dessa seção, apresentou-se propostas de possíveis discussões futuras que podem vir a contribuir com as áreas em comento.

Além das contribuições teóricas, as contribuições práticas se resumem em: estimular maior participação de atores no desenvolvimento de inovação social no contexto das empresas sociais, utilizar a internet e a tecnologia como aliadas para a produção e o dimensionamento dessas inovações, formar redes com atores de diversos setores distintos, e por fim, investir em conhecimento sobre inovações sociais, pois por falta desse conhecimento, empreendedores sociais, possuem dificuldades em desenvolver tal inovação, ou inclusive desconhecem a sua existência. 
As principais limitações desse estudo estão associadas à escolha metodológica de utilizar apenas uma única base de dados, à natureza qualitativa da maioria dos trabalhos de pesquisa que foram utilizadas nesta revisão e o viés amostral dos estudos selecionados que pode influenciar a validade dos resultados discutidos. Consequentemente, as conclusões apontadas sobre a relação entre as perspectivas exigem mais pesquisas.

Adicionalmente, ainda foi possível identificar uma série de caminhos para futuras pesquisas sobre empreendedorismo social e inovação social. Essas sugestões são baseadas em perguntas abertas encontradas durante análise dos resultados nos artigos discutidos. Fundamentado nisso, sugere-se analisar se existem diferenças fundamentais nos antecedentes da inovação social e empreendedorismo social (Lortie \& Cox, 2018), tendo em vista que ainda há inconsistências entre os limites conceituais entre ambas as temáticas. Para sanar tais problemas há a necessidade de compreender atos ou fatos passados que deram origem a esses assuntos realizando um processo comparativo identificando as semelhanças e diferenças entre eles.

Pesquisas que gerem dados substanciais sobre o tamanho, escala e impacto do empreendedorismo social e inovação social, bem como investiga-los dentro de uma variedade de fatores socioeconômicos, culturais, locais, ambientes regionais e políticos (Shaw \& Bruin, 2013). Além disso, ainda não está claro até que ponto as diferenças culturais interferem no empreendedorismo social e na inovação social, havendo a necessidade de pesquisas futuras que melhorem a compreensão de como as diferenças culturais são gerenciadas.

\section{Referências}

Alexandre-Leclair, L. (2017). Social entrepreneurship and social innovation as a tool of women social inclusion and sustainable heritage preservation: the case of the Sougha Establishment in UAE. International Journal of Entrepreneurship and Small Business, 31(3), 345-362.

Atallah, A. N., \& Castro, A. A. (1998). Revisão sistemática da literatura e metanálise. Medicina baseada em evidências: fundamentos da pesquisa clínica. São Paulo: Lemos-Editorial, 42-8..

Austin, J., Stevenson, H., \& Wei-Skillern, J. (2012). Social and commercial entrepreneurship: same, different, or both?. Revista de Administração, 47(3), 370-384.

Bhatt, P., \& Altinay, L. (2013). How social capital is leveraged in social innovations under resource constraints?. Management Decision, 51(9), 1772-1792.

Bignetti, L. P. (2011). As inovações sociais: uma incursão por ideias, tendências e focos de pesquisa. Ciências Sociais Unisinos, 47(1), 3-14.

Bouncken, R. B., Gast, J., Kraus, S., \& Bogers, M. (2015). Coopetition: a systematic review, synthesis, and future research directions. Review of Managerial Science, 9(3), 577-601.

Cajaiba-Santana, G. (2014). Social innovation: Moving the field forward. A conceptual framework. Technological Forecasting and Social Change, 82, 42-51.

Choi, N., \& Majumdar, S. (2014). Social entrepreneurship as an essentially contested concept: Opening a new avenue for systematic future research. Journal of business venturing, 29(3), 363-376.

Cunha, J., \& Benneworth, P. (2014). Social entrepreneurship and social innovation: are both the same?. In ICOPEV International Conference on Project Economic Evaluation (pp. 75-84). Universidade do Minho.

Dacin, M. T., Dacin, P. A., \& Tracey, P. (2011). Social entrepreneurship: A critique and future directions. Organization science, 22(5), 1203-1213.

Dacin, P. A., Dacin, M., \& Matear, M. (2010). Do we need a theory of social entrepreneurship. Academy of Management Perspectives, 24(3), 37-57. 
Dawson, P., \& Daniel, L. (2010). Understanding social innovation: a provisional framework. International Journal of Technology Management, $51(1), 9-21$.

Dees, J. G. (1998). The meaning of "social entrepreneurship" (Stanford University, Draft report for the Kauffman Center for Entrepreneurial Leadership).

Des, J. G. (2001). The meaning of "social entrepreneurship" (Draft paper). Disponível em: <http://www.caseatduke.org/documents/dees_sedef.pd>. Acesso em: 20 jan. 2017.

Denyer, D \& Tranfield, D. (2009). Producing a systematic review. The Sage Handbook of Organizational Research Methods. 671-689.

Dwivedi, A., \& Weerawardena, J. (2018). Conceptualizing and operationalizing the social entrepreneurship construct. Journal of Business Research, 86, 32-40.

Grohs, S., Schneiders, K., \& Heinze, R. G. (2017). Outsiders and Intrapreneurs: The Institutional Embeddedness of Social Entrepreneurship in Germany. VOLUNTAS: International Journal of Voluntary and Nonprofit Organizations, 28(6), 2569-2591.

Hota, P. K., Subramanian, B., \& Narayanamurthy, G. (2019). Mapping the Intellectual Structure of Social Entrepreneurship Research: A Citation/Co-citation Analysis. Journal of Business Ethics, 1-26.

Jäger, U. P., \& Schröer, A. (2014). Integrated organizational identity: A definition of hybrid organizations and a research agenda. VOLUNTAS: International Journal of Voluntary and Nonprofit Organizations, 25(5), 1281-1306.

Johnson, K., \& Lee, H. (2013). Impact investing: A framework for decision making. Boston: Cambridge Associates LLC.

Juliani, D. P., Juliani, J. P., de Souza, J. A., \& Harger, E. M. (2014). Inovação social: perspectivas e desafios. Revista ESPACIOS|Vol. 35 (No 5) Año 2014.

Justen, G. S., Teixeira, R. M., \& Segatto, A. P. (2018). Empreendedorismo social e inovação social: convergências e diferenças conceituais. Encontro Internacional sobre Gestão Ambiental e Meio Ambiente - XX ENGEMA. Anais...São Paulo.

Lettice, F., \& Parekh, M. (2010). The social innovation process: themes, challenges and implications for practice. International Journal of Technology Management, 51(1), 139-158.

Lortie, J., \& Cox, K. C. (2018). On the boundaries of social entrepreneurship: A review of relationships with related research domains. International Entrepreneurship and Management Journal, 14(3), 639-648.

Lubberink, R., Blok, V., van Ophem, J., van der Velde, G., \& Omta, O. (2018). Innovation for Society: Towards a Typology of Developing Innovations by Social Entrepreneurs. Journal of Social Entrepreneurship, 9(1), 52-78.

Macke, J., Sarate, J. A. R., Domeneghini, J., \& da Silva, K. A. (2018). Where do we go from now? Research framework for social entrepreneurship. Journal of cleaner production, 183, 677-685.

Mair, J., \& Marti, I. (2006). Social entrepreneurship research: A source of explanation, prediction, and delight. Journal of world business, 41(1), 36-44.

Marshall, R. S. (2011). Conceptualizing the international for-profit social entrepreneur. Journal of Business Ethics, 98(2), 183-198.

Medeiros, C. B., Ribeiro Machado, L. C., Araújo Pereira, L. C., Almeida Costa, Í. C., \& Pasa Gomez, C. (2017). Inovação Social e Empreendedorismo Social: Uma Análise Sob a Perspectiva da Economia Solidária. GESTÃO. Org: Revista Eletrônica de Gestão Organizacional, 15(1).

Mirvis, P., \& Googins, B. (2018). Catalyzing Social Entrepreneurship in Africa: Roles for Western Universities, NGOs and Corporations. Africa Journal of Management, 4(1), 57-83. 
Mulgan, G. (2006). The process of social innovation. Innovations: technology, governance, globalization, 1(2), 145-162.

Mueller, S., D’Intino, R. S., Walske, J., Ehrenhard, M. L., Newbert, S. L., Robinson, J. A., \& Senjem, J. C. (2015). What's holding back social entrepreneurship? Removing the impediments to theoretical advancement. Journal of social entrepreneurship, 6(3), 245-256.

Muhamad, N. S. A., \& Adham, K. A. (2013). Social entrepreneurship as transformative service for societal well-being. Jurnal Pengurusan (UKM Journal of Management), 39.

Munshi, N. V. (2010). Value creation, social innovation, and entrepreneurship in global economies. Journal of Asia-Pacific Business, 11(3), 160-165.

Murray, R., Caulier-Grice, J., \& Mulgan, G. (2010). The open book of social innovation (p. 2). London: National endowment for science, technology and the art.

Nandan, M., London, M., \& Bent-Goodley, T. (2015). Social workers as social change agents: Social innovation, social intrapreneurship, and social entrepreneurship. Human Service Organizations: Management, Leadership \& Governance, 39(1), 38-56.

Newth, J., \& Woods, C. (2014). Resistance to social entrepreneurship: How context shapes innovation. Journal of Social Entrepreneurship, 5(2), 192-213.

Nicholls, A. 2006. "Introduction.” In A. Nicholls (Ed.), Social Entrepreneurship: New Models of Sustainable Social Change. Oxford: Oxford University Press

Nicholls, A., \& Murdock, A. (2012). The nature of social innovation. In social innovation (pp. 1-30). Palgrave Macmillan, London.

Phillips, W., Lee, H., Ghobadian, A., O’Regan, N., \& James, P. (2015). Social innovation and social entrepreneurship: A systematic review. Group \& Organization Management, 40(3), 428-461.

Phills, J. A., Deiglmeier, K., \& Miller, D. T. (2008). Rediscovering social innovation. Stanford Social Innovation Review, 6(4), 34-43.

Pol, E., \& Ville, S. (2009). Social innovation: Buzz word or enduring term?. The Journal of socioeconomics, 38(6), 878-885.

Rao-Nicholson, R., Vorley, T., \& Khan, Z. (2017). Social innovation in emerging economies: A national systems of innovation based approach. Technological Forecasting and Social Change, 121, 228-237.

Saebi, T., Foss, N. J., \& Linder, S. (2019). Social entrepreneurship research: Past achievements and future promises. Journal of Management, 45(1), 70-95.

Sampaio, R. F., \& Mancini, M. C. (2007). Systematic review studies: a guide for careful synthesis of the scientific evidence. Brazilian Journal of Physical Therapy, 11(1), 83-89.

Shaw, E., \& de Bruin, A. (2013). Reconsidering capitalism: the promise of social innovation and social entrepreneurship?. International Small Business Journal, 31(7), 737-746.

Schumpeter, J. (1985). Teoria do desenvolvimento economico: Uma investigaçao sobre lucro, capital, credito, juro e ciclo economico. nova cultural.

Sassmannshausen, S. P., \& Volkmann, C. (2013). A bibliometric based review on social entrepreneurship and its establishment as a field of research (No. 2013-003). Schumpeter Discussion Papers.

Srivetbodee, S., Igel, B., \& Kraisornsuthasinee, S. (2017). Creating Social Value Through Social Enterprise Marketing: Case Studies from Thailand's Food-Focused Social Entrepreneurs. Journal of Social Entrepreneurship, 8(2), 201-224. 
Tan, W. L., Williams, J., \& Tan, T. M. (2005). Defining the 'social'in 'social entrepreneurship': Altruism and entrepreneurship. The International Entrepreneurship and Management Journal, 1(3), 353-365.

Thompson, J. L. (2008). Social enterprise and social entrepreneurship: where have we reached? A summary of issues and discussion points. Social Enterprise Journal, 4(2), 149-161.

Thoene, U., \& Turriago Hoyos, Á. (2017). Financial inclusion in Colombia: A scoping literature review. Intangible capital, 13(3), 582-514.

Tracey, P., \& Stott, N. (2017). Social innovation: a window on alternative ways of organizing and innovating. Innovation, 19(1), 51-60.

Tranfield, D., Denyer, D. and Smart, P. (2003) "Towards a methodology for developing evidenceinformed management knowledge by means of systematic review", British Journal of Management, Vol. 14, No.3, pp.207-222.

Toivonen, T. (2016). What is the social innovation community? Conceptualizing an emergent collaborative organization. Journal of Social Entrepreneurship, 7(1), 49-73.

Vo, A. T., Christie, C. A., \& Rohanna, K. (2016). Understanding evaluation practice within the context of social investment. Evaluation, 22(4), 470-488.

Weerawardena, J., \& Mort, G. S. (2012). Competitive strategy in socially entrepreneurial nonprofit organizations: Innovation and differentiation. Journal of Public Policy \& Marketing, 31(1), 91-101.

Westley, F., \& Antadze, N. (2010). Making a difference: Strategies for scaling social innovation for greater impact. Innovation Journal, 15(2).

Westwood, A. (2009). User led innovation-a future for social policy. Centro de Informação e Documentação (CID) and EQUAL Portugal (Eds.), Social innovation, 38-53.

Witkamp, M. J., Raven, R. P., \& Royakkers, L. M. (2011). Strategic niche management of social innovations: the case of social entrepreneurship. Technology Analysis \& Strategic Management, 23(6), 667681.

Zahra, S. A., Gedajlovic, E., Neubaum, D. O., \& Shulman, J. M. (2009). A typology of social entrepreneurs: Motives, search processes and ethical challenges. Journal of business venturing, 24(5), 519-532.

Zainudin, A., Raja Suzana, R. K., \& Zulazli, H. (2017). Modelling Social Innovation for Young Entrepreneurs Living in the Marginalised Communities in Malaysia. PERTANIKA Journal of Social Science \& Humanities (JSSH), 25, 111-122.

Zebryte, I., \& Jorquera, H. (2017). Chilean tourism sector "B Corporations": evidence of social entrepreneurship and innovation. International Journal of Entrepreneurial Behavior \& Research, 23(6), 866-879.

Zulazli, H., Raja Suzana, R. K., Zainudin, A., Abang Feizal, A. I., \& Mokhtarrudin, A. (2017). The Impact of Social Innovation on an Enterprise Success: Item Validation. Pertanika Journal of Social Sciences \& Humanities, 25. 